108

\title{
Review: a peridischarge multidisciplinary treatment programme reduces readmissions in heart failure
}

Gwadry-Sridhar FH, Flintoft V, Lee DS, et al. A systematic review and meta-analysis of studies comparing readmission rates and mortality rates in patients with heart failure. Arch Intern Med 2004;164:2315-20.

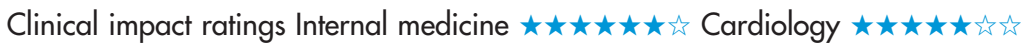

In patients who have been admitted with heart failure, is a peridischarge multidisciplinary treatment programme more effective than usual care for reducing rates of readmission and all cause mortality?

\section{METHODS}

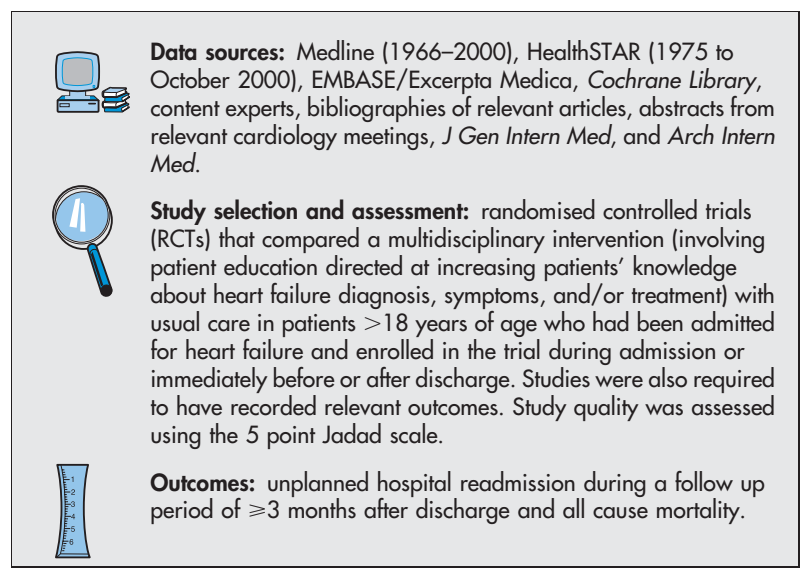

\section{MAIN RESULTS}

8 RCTs $(\mathrm{n}=1246)$ (mean age $75 \mathrm{y}, 52 \%$ women) met the selection criteria. Before discharge, the multidisciplinary intervention comprised visits by registered nurses, dietitians, geriatric cardiologists, or research pharmacists who educated patients about heart failure symptoms, medications, treatment, diet (eg, sodium fluid restrictions), and research in progress. Education was also provided in form of booklets and oral/video sessions. After discharge, patients were visited by home care nurses or cardiology nurses, were invited to attend nurse directed outpatient clinics, or were interviewed by nurses over the phone during a follow up period of 24 hours to 9 months. During these contacts, patients received repeat education and/or a cardiac physical examination. Meta-analysis was done using a random effects model. The rate of readmission was lower in the intervention group than in the control group (table). The groups did not differ for all cause mortality (Table).

For correspondence: Dr F H Gwadry-Sridhar, University of Western Ontario and London Health Sciences Centre, London, Ontario, Canada. Femida.GwadrySridhar@lhsc.on.ca

Sources of funding: Heart and Stroke Foundation of Canada and Canadian Institutes of Health Research.

\section{CONCLUSIONS}

In patients who have been admitted with heart failure, a peridischarge multidisciplinary treatment programme is more effective than usual care for reducing rates of readmission. However, the groups did not differ for all cause mortality.

\section{Commentory}

$\mathrm{H}$ eart failure is recognised as the most frequent and expensive cause of hospital admission in patients $>65$ years of age. Thus efforts to reduce hospital admission for heart failure either by developing new pharmacological or mechanical/electrical treatment approaches and/or more efficient application of previously proven strategies are important.

Several small RCTs have shown that physician and/or nurse management programmes are effective in reducing hospital admission for heart failure, mainly by ensuring optimum usage and dosing of proven pharmacological strategies. ${ }^{.}$The meta-analysis by Gwadry-Sridhar et al of 8 RCTs involving approximately 1250 patients confirms the effectiveness of heart failure management programmes for reducing hospital readmission rates (table). Although the meta-analysis did not show an effect of these programmes on all cause mortality, it could be anticipated that appropriate use of proven pharmacological strategies and optimal dosing should result in a reduction in total mortality.

However, the effectiveness of these programmes is likely to diminish in the future with increased use of data automation and quality assurance techniques designed to improve and streamline the overall quality of care. A major reduction in hospital admission for heart failure will come over the long term from a better understanding of the pathophysiology of heart failure and the development of new pharmacological and/or electrical/mechanical strategies. The ultimate solution to the epidemic of heart failure and its increasing health care burden is prevention. Better control of hypertension and other cardiovascular risk factors will in the long run have the greatest effect on the economic burden associated with heart failure. Until such time, efforts to broaden the applicability and cost effectiveness of heart failure management programmes should be encouraged.

Bertram Pitt, MD University of Michigan School of Medicine Ann Arbor, Michigan, USA

1 Gonseth J, Guallar-Castillon P, Banegas JR, et al. The effectiveness of disease management programmes in reducing hospital re-admission in older patients with heart failure: a systematic review and meta-analysis of published reports. Eur Heart J 2004;25:1570-95.

A peridischarge multidisciplinary invervention $v$ usual care in inpatients with heart failure at 3-12 months*

\begin{tabular}{|c|c|c|c|c|}
\hline \multirow[b]{2}{*}{ Outcomes } & \multicolumn{2}{|c|}{ Weighted event rates } & \multirow[b]{2}{*}{$\operatorname{RRR}(95 \% \mathrm{Cl})$} & \multirow[b]{2}{*}{ NNT (Cl) } \\
\hline & Intervention & Control & & \\
\hline $\begin{array}{l}\text { Hospital readmission } \\
\text { All cause mortality }\end{array}$ & $\begin{array}{l}38.2 \% \\
18.4 \%\end{array}$ & $\begin{array}{l}49.2 \% \\
19.4 \%\end{array}$ & $\begin{array}{l}21 \%(9 \text { to } 32) \\
2 \%(-34 \text { to } 28)\end{array}$ & $\begin{array}{l}10 \text { (6 to } 17) \\
\text { Not significant }\end{array}$ \\
\hline
\end{tabular}

*Abbreviations defined in glossary; weighted event rates and $\mathrm{Cl}$ calculated from data in article using a random effects model. 